Марина Чиханова

С.- Петербургский государственный

университет аэрокосмического

приборостроения

Гуманитарный факультет

Кафедра иностранных языков

chikhanova.m.a@gmail.com
ORIGINAL RESEARCH PAPER

UDK 811.112.2'367:004.43

DOI: $10.19090 / \mathrm{mv} \cdot 2017.8 .311-327$

\title{
АЛГОРИТМИЧЕСКАЯ ГРАММАТИКА: СИНТАКСИЧЕСКОЕ МЕСТО И ЕГО РОЛЬ ПРИ АНАЛИЗЕ НЕМЕЦКОГО ПРЕДЛОЖЕНИЯ
}

\begin{abstract}
АННОТАЦИЯ
Одним из современных подходов в преподавании иностранного языка в условиях ограниченного количества времени является преподавание на основе грамматических алгоритмов. Грамматические алгоритмы построены с учетом формальных признаков различных грамматических явлений, предписывают строгую последовательность выполнения действий и дают возможность быстро извлекать информацию из текста, т.е. работа с текстом идет по пути «от формы к смыслу». Студенты приступают к переводу текста не с поиска значений слов в словаре, а с определения позиций (мест), занимаемых словами в предложении. Однако возникают такие явления, для которых необходимо создание новых алгоритмов. Например, алгоритм, связанный с понятием синтаксического места, центральным для немецкого предложения, или алгоритм, позволяющий определить, занимает ли группа существительного с предлогом «старую» позицию или «новую».
\end{abstract}

Ключевые слова: преподавание иностранного языка, немецкий язык, система обучения, алгоритмическая грамматика, алгоритм, формальные признаки, синтаксическое место, группа существительного, цепочка групп существительного, предлог.

\section{GRAMMAR IN ALGORITHMS: SYNTACTIC POSITION AND ITS ROLE IN ANALYSIS OF THE GERMAN SENTENCES}

\begin{abstract}
One of the modern methods of foreign language teaching wtih limited time conditions is the teaching based on grammatical algorithms. Grammatical
\end{abstract}


algorithms are constructed with taking into consideration the formal signs of different grammatical phenomena. They need the special order of actions ofr the fulfilment and give the opportunity to get the information from the text quickly, i.e. the with the text goes 'from form to meaning'. The experience of teaching German language based on the algorithmic approach proves the productivity and effectiveness of suggested teaching method. During the process of teaching it is explained that a minimum number of grammatical terms are used. The algorithmic rule is based on formal characteristics. It should be brief, without exceptions and easy to remember. Grammatical algorithms covering the main grammatical rules are created earlier. However, there are some grammatical phenomena when we have to create new algorithms. For example, the algorithm connected with the definition of the syntactic position which is central for German sentences, or an algorithm which permits to define whether the noun group with a preposition occupies the 'old' position or 'new' one.

Keywords: foreign language teaching, German, learning system, grammar in algorithm, algorithm, formal signs, syntactic position, noun group, noun chain groups chain, preposition.

\section{1. ИЗМЕНЕНИЕ ПОДХОДА К ПРЕПОДАВАНИЮ ИНОСТРАННОГО ЯЗЫКА В РЯДЕ РОССИЙСКИХ УНИВЕРСИТЕТОВ}

Современному специалисту - инженеру, экономисту, юристу чрезвычайно важно получать доступ к различным специализированным источникам информации, поэтому от него требуется знание иностранного языка. Он постоянно должен быть в курсе новых разработок, читать газеты, статьи в профильных журналах, в интернете и т.д. Кроме того, владение иностранным языком, даже на уровне чтения и понимания литературы по специальности, является несомненным конкурентным преимуществом. Поэтому при обучении иностранному языку в настоящее время требуются качественно новые ориентиры в преподавании иностранного языка, в частности, в тех вузах или на факультетах, где иностранный язык не является специальностью.

Безусловно, в основе традиционных форм преподавания стоит сложнейший процесс, в котором применяется множество разнообразных подходов, способов, средств предоставления и получения знаний. В каждом из этих подходов или методов преподавания заключена своя педагогическая философия и свой набор педагогических приемов. Но если говорить о традиционных формах преподавания иностранных языков, то, к сожалению, 
они себя исчерпали, потому что не приводят к тому результату, который позволит самостоятельно, уже после окончания университета, знакомиться с нужной информацией по специальности на иностранном языке. Обращение к современным средствам машинного перевода также себя не оправдывает, потому что машина пока еще не научилась различать ни смысловые нюансы, ни терминологические синонимы, ни формальные признаки построения, например, немецкого предложения. Дело в том, что именно знание формальных признаков помогает перейти к пониманию смысла. Именно для того, чтобы изменить представления студентов о том, что можно научиться довольно быстро читать и переводить тексты по специальности, в Санкт-Петербургском государственном университете экономики и финансов (ныне Санкт- Петербургский государственный экономический университет), а позже и в Санкт-Петербургском государственном университете аэрокосмического приборостроения было принято решение использовать алгоритмический подход при обучении магистрантов иностранному языку.

Подавляющее большинство студентов вузов в школе изучали английский язык. Поэтому в Санкт-Петербургском экономическом университете было решено предложить магистрантам выбрать новый для них, например, немецкий язык. В Санкт-Петербургском университете аэрокосмического приборостроения магистранты продолжили изучать немецкий язык. Одной из причин такого решения является недостаточное количество часов иностранного языка во время обучения по бакалаврским программам. Учебным планом предусмотрено изучение иностранного языка на первых двух курсах, а изучение профильных предметов начинается только с 3 курса. Поэтому предлагать студентам для чтения специализированные тексты в это время не имеет смысла, у них еще нет достаточных базовых знаний по выбранной специальности.

Любая система обучения будет иметь смысл только в том случае, если в центр этой системы поставить ключевое понятие, вокруг которого будут группироваться все объяснения. Таким ключевым понятием стал для нас грамматический алгоритм. В языке есть две закономерности - экономии и избыточности. В языковом алгоритме идея экономии и идея избыточности соединены. Когда функция алгоритма будет активирована, обучающийся сам на базе предложенных алгоритмических схем начнет быстро и верно анализировать текст на не знакомом для него языке. 
О том, что представляет собой алгоритмический подход в преподавании иностранных языков, и как знание формальных признаков облегчает понимание смысла предложения и, в конечном счете текста, речь пойдет в разделе 2 .

\section{2. АЛГОРИТМИЧЕСКАЯ ГРАММАТИКА: ОТ ФОРМЫ К СМЫСЛУ}

В 60-ые годы ХХ века А. Р. Белопольской был проведен ряд исследований, целью которых было разработать принципы и методы построения грамматики для читающего текст на немецком языке. Правила анализа текста базируются на лингвистических исследованиях по выделению формальных признаков различных языковых явлений. Основываясь исключительно на формальных признаках текста, был создан ряд грамматических алгоритмов, составивших основу алгоритмической грамматики (Белопольская 1971, Белопольская 2014).

Появление самого слова «алгоритм» связано с именем Мухаммеда ибн Муса аль - Хорезми, которого считают основателем классической алгебры. Идея Хорезми заключалась в том, что решение любой задачи может быть найдено путем выполнения правил в строго прописанной последовательности. Поэтому алгоритмом стали называть точное и понятное предписание или описание последовательности действий, строгое исполнение которых приводит к решению поставленной задачи за определенное количество конечных шагов. Алгоритм оказался очень продуктивным способом поиска общих методов решения однотипных задач. Он предписывает определенную закономерность осуществления шагов, которые ведут к однозначному результату и требуют только однозначный ответ: «да»/ «нет». Нетипичные случаи и исключения рассматриваются особо, для них составляется особый алгоритм (так называемый алгоритм Б) или, если точный алгоритм составить невозможно, даются специальные разъяснения.

Н. Хомский в середине прошлого века в монографии «Синтаксические структуры» высказал идею о неравнозначности и неэквивалентности понятий «грамматичность» и «осмысленность» и привел пример: «Бесцветные зеленые идеи спят яростно» (англ. "Colorless green ideas sleep furiously"), доказывая, что не каждое грамматически правильное предложение имеет понятный всем смысл, но что любое грамматически правильное предложение носитель языка поймет с точки зрения логики, 
логических связей в предложении. (Хомский 1962, Хомский, Миллер 2003) Установить такие связи носителю языка труда не составляет. Подобную идею, но гораздо раньше Н. Хомского, в 20-ые годы XX века высказал академик Л. В. Щерба, предложив ставшую классической фразу «Глокая куздра штеко будланула бокра и курдячит бокрёнка». Любой носитель русского языка, опираясь исключительно на формальные признаки, поймет, о чем идет речь в этом правильном для русского языка предложении. Формальными признаками, помогающими ему в этом, являются: место слова в предложении, согласование слов в предложении, окончания глагола, существительного, наречия, прилагательного: кто? - куздра, - куздра какая? - глокая - куздра что сделала? - будланула - будланула кого? бокра - будланула как? - штеко - что делает сейчас? - курдячит курдячит кого? - бокрёнка.

Р. Якобсон, возражая Н. Хомскому, писал, что подобные предложения нельзя считать бессмысленными, поскольку можно установить логические связи в предложении (Якобсон 1985). Пример Л. В. Щербы подтверждает эту мысль Р. Якобсона.

Опыт обучения иностранному (в частности, немецкому) языку на основе алгоритмического подхода показывает, что такой путь гораздо более продуктивен и дает возможность обучающимся практически с первых занятий понять логику изучаемого языка, получить системные сведения о нем. Студенты, перед которыми стоит задача прежде всего понять форму предложения, не отвлекаются на поиски значения слова в словарях, не теряются в многозначности слов, не собирают предложение из разрозненных слов, пытаясь «разгадать головоломку», т. е. «докопаться» до смысла, заключенного в предложении. Практически все грамматические явления получают логическое объяснение через алгоритмы, благодаря которым правила легче запоминаются.

Для изучающего иностранный язык важна такая грамматика, которая делает упор не на теоретические знания о языке, а на практическое применение правил. В этом и есть основное преимущество грамматики, построенной на алгоритмах. Такой путь способствует, например, развитию навыков перевода и при переводе письменного текста, и при устном, в частности, при синхронном переводе, когда важен так называемый навык прогнозирования, при котором переводчик по формальным признакам может догадаться или предположить, что последует дальше и таким образом 
строить свой перевод. Более того, целесообразность алгоритмического подхода к обучению, предполагающего системное усвоение знаний, принятие решений на основе готовых алгоритмов путем выполнения действий по четко установленным правилам, подчеркивается и переводчиками (Мирам 2005).

Вернемся к тексту. Цель чтения текста всегда одна - его смысл должен быть понят. Читающий текст традиционно воспринимает структуру предложения последовательно, слово за словом. Но, «продвигаясь» по тексту, он получает информацию о содержании текста только после того, как по формальным признакам определит форму слов, последовательность их появления в предложении, их синтаксические, а в конечном счете, и смысловые связи. Поэтому от умения увидеть и проанализировать формальные признаки зависит понимание текста и его верный перевод. Читающий текст сможет уверенно идти от формы к пониманию смысла предложения и текста в целом, пользуясь грамматическими алгоритмами. Именно они помогают определить верное «пошаговое» движение по тексту. Языковые алгоритмы указывают, что и в какой последовательности нужно сделать, чтобы от понимания формы предложения перейти к пониманию его смысла и, в конечном счете, к пониманию смысла всего текста.

Итак, грамматический алгоритм - это инструмент, который подробно прописывает последовательность действий, называемых «шагами». Если не нарушать прописанную последовательность действий, они приведут к однозначному ответу на поставленные вопросы об определении грамматической формы и далее к пониманию смысла предложения и его переводу. Важно, чтобы алгоритмическое правило, построенное на формальных признаках, было кратким, по возможности не иметь исключений, легко запоминаться. Например, определение по артиклю рода, числа и падежа имени существительного, подлежащего, распространенного определения (Ямшанова 2017). Знание грамматических алгоритмов и умение ими пользоваться прочно ставит «с головы на ноги» все правила грамматики, вызывающие у студентов трудности при традиционном объяснении.

Грамматические алгоритмы, охватывающие основные грамматические правила, первой разработала А. Р. Белопольская и продолжила В. А. Ямшанова. Однако опыт преподавания немецкого языка на основе алгоритмической грамматики показывает, что постоянно 
возникают и такие явления, которые требуют объяснения и создания новых алгоритмов. Например, использование предлога für в функции Genitiv (родительного падежа) или довольно трудные грамматические явления, связанные с понятием синтаксического места. Безусловно, абсолютного алгоритма не может быть. Но для того, чтобы составить алгоритм, предусматривающий все основные «шаги», необходимо провести диагностику ошибок, которые чаще всего допускают студенты. В частности, такая диагностика важна при определении синтаксического места.

\section{3. ПОНЯТИЕ «СИНТАКСИЧЕСКОГО МЕСТА»}

Принципиальным при анализе немецкого предложения является понятие «синтаксического места». Занимаемая словом позиция в предложении - очень сильный и очевидный формальный признак, который дает сигнал того, что воспринимать это слово следует как слово, занимающее в данном предложении единственно возможную позицию в определенном синтаксическом окружении. Именно грамматическое оформление предложения показывает, о ком или о чем идет речь в предложении, когда совершается действие, совершает ли это действие сам субъект или, напротив, действие совершается над субъектом, есть ли какиелибо обстоятельства, вызванные ситуацией, описываемой в этом предложении. Для того, чтобы ответить на все эти вопросы, необходимо определить места (позиции), которые занимают слова или группы слов в предложении. Можно сравнить определение синтаксического места с детским конструктором «Лего» или со сбором пазлов, когда из отдельных мелких деталей при условии их правильного сочетания может получиться какая-нибудь фигура или картина на заданную тему. Также происходит и при переводе немецкого предложения: определив с помощью формальных признаков позиции, занимаемые словами в предложении, их управление, а также в какой зависимости они находятся друг от друга, можно приступать к поиску значений слов в словаре и «конструированию» перевода. Но уже не на основе догадок, а на основе тщательно выполненного анализа синтаксической структуры переводимого предложения.

Можно говорить об универсальности такого подхода, потому что и при анализе предложения русского языка можно идти таким же путем, т. е. отталкиваться от позиции, занимаемой словом или сочетанием слов в предложении. Т. П. Ломтев, например, в качестве элементарной 
синтаксической единицы предлагал рассматривать не саму словесную форму, а занимаемую ею позицию в предложении и считать ее релевантной с точки зрения синтаксиса (Ломтев 1958). Следовательно, «синтаксическое место» - это позиция, занимаемая в предложении словом или сочетанием слов.

\section{1 Части речи в аспекте синтаксического места}

Прежде чем говорить об анализе синтаксической структуры немецкого предложения с позиции определения синтаксического места, необходимо указать, какие части речи могут занимать самостоятельное место в предложении, а какие никогда не будут выступать в качестве самостоятельной единицы. При этом сразу необходимо подчеркнуть, что одно место в предложении могут занимать и одно слово, и несколько слов. Поэтому, определяя границы синтаксического места, нужно работать не с отдельными словами, а с «местами», т.е. с занимаемой словом или группой слов позицией в предложении. Самостоятельное место в предложении могут занимать:

- слово;

- словосочетание;

- предложение;

- оборот.

Самостоятельное место в предложении всегда занимают:

- имя существительное (С) или группа имен существительных (группа С);

- глагол в любой форме;

- приставка, если она отделена от глагола;

- местоимение - заместитель существительного;

- союзное слово.

Самостоятельного места никогда не занимают:

- артикли;

- предлоги;

- прилагательное и причастие в функции левого или правого определения;

- местоимение - заместитель прилагательного. 
Все они входят в группу существительного и занимают с ним одно место. Одно место могут занимать и несколько групп существительных:

Für Technik-Freaks | ist | es | eine besondere Herausforderung ${ }^{1}$.

Sie | erleichtern | den Zugang zu Informationen und Dienstleistungen.

В группу существительного входит само существительное и все относящиеся к нему слова, стоящие от него слева и справа, если существительное имеет правое определение. О правом и левом определении речь пойдет ниже, в п. 3.2.

Итак, одно место в немецком предложении может занимать группа существительного или цепочка групп существительного. Проблема для изучающего немецкий язык заключается в том, чтобы верно определить границы группы существительного или нескольких групп существительного, входящих в предложение, т. е. определить, где заканчивается одна группа существительного и начинается следующая.

Союз не занимает места, другими словами, он занимает нулевое («Ø») место:

<Ein Dialog ist so zu gestalten>, dass <er den Benutzer bei der Erledigung seiner Arbeit unterstützt und nicht zum eigenständigen Problem wird>.

Словом, которое не всегда занимает самостоятельное место, является наречие:

- оно не занимает самостоятельного места внутри группы C: die seinerzeit vorstellbaren

Grenzen (мыслимые ранее границы)

- оно занимает самостоятельное место вне группы $\mathrm{C}$ и управляется глаголом.

Ср. предложение: Laptops überflügeln in ihrer Leistung | die seinerzeit vorstellbaren

Grenzen |, verbinden sich überall in der Welt drahtlos mit dem Internet, und können wahlweise per Tastatur, Maus, Touchpad oder Stift gesteuert werden.

Здесь наречия управляются глаголами verbinden sich $\rightarrow$ wo? $\rightarrow$ überall $\rightarrow$ wie? $\rightarrow$ drahtlos

\footnotetext{
${ }^{1}$ Все приводимые в статье примеры взяты из аутентичных немецких источников.
} 


\section{können $\rightarrow$ wie? $\rightarrow$ wahlweise $\rightarrow$ gesteuert werden (соединяются где? \\ $\rightarrow$ повсеместно $\rightarrow$ \\ как? $\rightarrow$ без провода; могут управляться как? $\rightarrow$ по выбору).}

3.2 Члены предложения в аспекте синтаксического места

Алгоритм должен быть в известной степени «пошаговым», подсказывающим последовательность выполнения действий. Например, в алгоритме действий, связанных с членами предложения и определением синтаксического места, важно определить места, занимаемые:

1) сказуемым: в немецком языке это всегда второе и последнее место в главном (простом) предложении ${ }^{2}$. Причем, на втором месте глагол всегда стоит либо в форме Präsens, либо в форме Präteritum ${ }^{3}$, а на последнем месте стоит Partizip II, Infinitiv или отделяемая приставка:

Für die Sprecher einer Sprache stellt diese einen Baustein der eigenen Identität dar.

Elf Spitzenforscher haben im Rahmen des Star Tiger-Projektes der Europäischen

Raumfahrtorganisation ESA eine kompakte Kamera konstruiert.

2) подлежащим, a это, как известно, в главном (простом) предложении может быть

- либо I-ое место:

Der nächste, wichtige Punkt ist die Art der Speisung des Strahlers.

Das Hauptziel dieser Arbeit ist die Entwicklung eines steuerbaren und intelligenten

Antennensystems mit großer Flexibilität, die....

Der selbst rotierende Erdkern sorgt für ein starkes Magnetfeld, das den Planeten vor den

Auswirkungen des Sonnenwindes schützt.

\footnotetext{
${ }^{2}$ Предпочтительно использовать термин «главное предложение», избегая сочетания «простое предложение», т. к. по существу «главное предложение» и «простое предложение» для немецкой грамматики одно и то же.

${ }^{3}$ Формальные признаки, позволяющие отличать формы Präsens и Präteritum, отрабатываются специальным алгоритмом на ранних этапах обучения.
} 
- либо III-е место:

Beim Dateiscan vergleicht ein Virenscanner den Inhalt der Dateien mit bestimmten Mustern in

seiner Virendatenbank.

Auch sein Ausgangspunkt war die Belastung durch langwierige Rechenarbeiten bei seiner

wissenschaftlichen Tätigkeit.

3) определением. Здесь необходимо сделать следующее замечание. Исходя из того, что

для обучающегося важно практическое применение правил, количество грамматических

терминов ${ }^{4}$ сведено до минимума и используются только самые основные - подлежащее,

сказуемое и определение. Что касается определения, то вслед за А.

Р. Белопольской мы

различаем левое определение и правое определение. Левым определением всегда будет:

- либо прилагательное (в полной форме):

enorme Rechenleistung, fantastische Grafikfähigkeiten und drahtlose

Netzwerkverbindungen...;

- либо причастие (в полной форме):

die vorgestellte Studie, der rotierende Erdkern, orientiertes System.

Правое определение выражено группой существительного обычно в родительном падеже:

die enorme Größe des Erdmondes, die Herstellung einer neuen

\section{Ordnung der Lochkarten}

Любое существительное может иметь как левое, так и правое определения:

Seit über 100 Jahren ist ein enormes Wachstum der wissenschaftlichen Literatur sichtbar.

Das explosionsartige Wachstum des Wissens ereignet sich nicht nur innerhalb der traditionellen

\footnotetext{
4 Мы специально свели к минимуму использование на занятиях традиционных грамматических терминов: косвенное дополнение, обстоятельство (места, времени, образа действия), спрягаемая и неспрягаемая части сказуемого, обособленный причастный оборот и т. п.
} 
Fachdisziplinen.

Как известно, в немецком предложении очень важна так называемая глагольная рамка. В (главном) предложении место глагольной формы (Präsens/ Präteritum) является определяющим и задает сразу I и III места. Infinitiv, Partizip II, отделяемая приставка сразу задают последнее или предпоследнее место, т. е. части сказуемого расположены дистантно, показывая границы рамки, в которой расположены остальные позиции, занимаемые словами в предложении. Этому можно найти и культурологическое объяснение. В немецкой культуре все, по большому счету, определяется рамкой, начиная со строгих рамок поведения.

Таким образом, II-ое место является своеобразным индикатором границы синтаксического места, которому подчиняются все остальные места и определяя границы синтаксического места, состоящего из группы или цепочки групп существительного:

Подлежащее (Präs/ Prät) ...... ...... Part.II/Inf.

Der User (I) | muss (II) | immer mehr Zeit (III) | im Netz (IV) | verbringen (V).

\section{4. ОПРЕДЕЛЕНИЕ ГРАНИЦ СИНТАКСИЧЕСКОГО МЕСТА В ЦЕПОЧКЕ ГРУПП СУЩЕСТВИТЕЛЬНОГО}

Проблема при переводе немецкого предложения возникает на IIIем месте, если после него появляется цепочка групп существительного. Здесь следует выяснить, занимает ли каждая последующая группа существительных ту же самую или новую позицию. От этого зависит правильный перевод предложения, потому что перевод цепочки группы существительных в той же последовательности, что в немецком предложении, может привести к искажению смысла. Алгоритм определения границ цепочки групп существительного показывает, что необходимо определить, каким именно словом управляется каждая группа существительного.

Если группа существительного занимает ту же позицию, что и предшествующая, то она управляется ею и переводится сразу после нее. Если последующая группа существительного занимает новую позицию, то она управляется глаголом и переводится после того, как будет переведен сам глагол. Нарушение причинно-следственной связи приведет к неправильному переводу предложения. 
К формальным признакам «того же самого» места относятся:

$\mathrm{C}+\operatorname{des} \mathrm{C}^{5}$

Durch eine Verkettung.... stieg die Leistung des Reaktors plötzlich stark an (23).

$\mathrm{C}+\operatorname{der} \mathrm{C}$ (артикль не мужского рода ед.числа)

Die Pflanze kann ohne jede Form der Optimierung des Systems ...versorgen (37).

C+ предлог ,von“6

Der zweite sieht die Schaffung von organisatorischen Voraussetzungen... vor (6).

Формальные признаки «нового» места:

$\mathrm{C} \uparrow \operatorname{der} \mathrm{C}$ (артикль мужского рода ед.числа):

Dem Benutzer muss bei Bedarf $\uparrow$ der Zweck und der Leistungsumfang einer Funktion sowie

ihre Anwendung erläutert werden.

$\mathrm{C} \uparrow$ das $\mathrm{C}$

... muss an den Verstärkereingängen $\uparrow$ das (definierte) Testsignal eingespeist werden.

Besonders vorteilhaft sind aperturgekoppelte Resonatoren bei denen im Gegensatz zu einer

direkten oder elektrodynamischen Einspeisung $\uparrow$ das Netzwerk ... entkoppelt ist.

$\mathrm{C} \uparrow \operatorname{die} \mathrm{C}$

..., wobei auf der Digitalebene $\uparrow$ die Signale mehrerer Empfangsketten parallel von einem

digitalen Baustein verarbeitet werden können.

Dabei wurde neben der Raumtemperatur $\uparrow$ die Temperatur an einem Empfängergehäuse

ermittelt

\footnotetext{
5 Определенный артикль указан здесь как образец. Естественно, это может быть и неопределенный артикль, и заместители артикля (указательные, притяжательные местоимения и т.д.).

6 За исключением редких глаголов, управляющих существительным с предлогом von, например, abhängen von.
} 
$\mathrm{C} \uparrow \operatorname{dem} \mathrm{C}$

Wir können sicher sein, dass künftig noch abgelegenere Explosionen entdeckt werden, die ein

Fenster $\uparrow$ dem Ende des Dunklen Zeitalters des Universums öffnen.

$\mathrm{C} \uparrow \operatorname{den} \mathrm{C}$

Beim Dateiscan vergleicht ein Virenscanner $\uparrow$ den Inhalt der Dateien.

Dafür erlaubte die neue Bauweise $\uparrow$ den Einbau größerer Displays.

$\mathrm{C} \uparrow-\mathrm{C}$

Auf der Conference in Washington wurde die Frage gestellt, welchen Einfluss $\uparrow$ mobile

Technologien auf Geschäftsreisen haben.

S. F. B. Morse und J. M. Emile Baudot führten zur optimalen Nutzung der Telegrafenwege $\uparrow$

spezielle Codierungen der zu übermittelnden Information ein.

\section{5. ГРУППА СУЩЕСТВИТЕЛЬНЫХ С ПРЕДЛОГОМ В ЦЕПОЧКЕ ГРУПП СУЩЕСТВИТЕЛЬНЫХ}

Но гораздо чаще в цепочке групп существительных встречаются предложные группы, и правила, которые позволили бы различать, занимает предложная группа «старую» позицию или «новую» позицию, выработаны еще не до конца.

Например, как определить, какую именно позицию занимает в следующих предложениях предложная группа С в цепочке групп существительных:

- (1) Der Arbeitsspeicher | ist | ein wichtiger Teil eines Computers | und | ein wesentlicher Faktor $\leftarrow$ für die Leistungsfähigkeit eines Computersystems. Оперативная память - важная часть компьютера и существенный фактор $\rightarrow$ чего? $\rightarrow$ эффрективности компьютерной системы.

(2) Es sollte auf | die Einhaltung der Grenzwerte $\leftarrow$ für die Strahlung | bestanden

werden.

Необходимо было настоять на соблюдении предельных значений $\rightarrow$ чего? $\rightarrow$

излучения. 
(3) Der zweite Punkt sieht | die Schaffung von Voraussetzungen $\leftarrow$ für eine bessere Umsetzung

des wissenschaftlichen Potentials | vor. Второй пункт предусматривает создание условий

$\rightarrow$ чего? $\rightarrow$ лучшего использования научного потенциала.

- (4) In diesem Zusammenhang gilt mein Dank den Kollegen | für das gute Zusammenwirken und deren Beitrag bei Entwurf und Realisierung des Hardware-Demonstrators. $B$ связи $с$ этим я выражаю свою

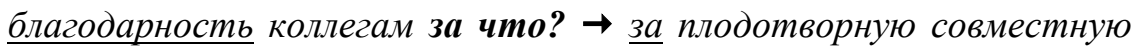
работу и их вклад в разработку и реализачию демонстратора программного обеспечения.

- (5) Von Deutschland aus bräuchte man mit dem Auto | für die gut 1800 Kilometer zum Ort des nuklearen Schreckens um die 20 Stunden. Если ехать из Германии, понадобилось бы примерно 20 часов для чего? $\rightarrow$ для того, чтобы преодолеть (букв. для преодоления) $1800 \mathrm{kм} \mathrm{на}$ автомобиле до места ядерной катастрофы.

(6) Bisher nicht berücksichtigt ist, dass nach Ablauf der Überflugzeit | für eine

Antennenkeule ein Wechsel zu einer anderen Trägerfrequenz durchgeführt werden muss.

До сих пор не учитывается, что после окончания времени пролета следует для чего?

$\rightarrow$ для антенного луча выполнить переключение на другую тактовую частоту.

В качестве примеров приведены предложения, где в цепочке групп существительных присутствует существительное с предлогом für, который среди всего исследованного на данный момент материала оказался пока самым частотным, поэтому и попал в поле нашего зрения.

В первых трех примерах предлог für входит в ту группу существительного, которая занимает ту же самую позицию, что и предшествующее существительное и управляется им (Faktor für: фактор $\rightarrow$ чего? $\rightarrow$ эффективности; die Einhaltung der Grenzwerte für: соблюдение предельных значений $\rightarrow$ чего? $\rightarrow$ излучения; die Schaffung von Voraussetzungen für: создание условий $\rightarrow$ чего? $\rightarrow$ использования).

В следующих трех примерах (примеры 4-6) существительное с предлогом für занимает новое место и управляется глаголом (gelten, 
bräuchte, durchgeführt werden muss). Но значения предлогов в предложениях 1-3 и 4-6 различаются. И причина, как представляется, не в том, что предлог многозначен, а в том, что его значение по всей видимости определяется, в том числе, занимаемой позицией. Мы специально привели по три примера на каждую позицию, потому что, для того, чтобы сделать окончательные выводы, необходимо еще исследовать огромное количество аутентичного лингвистического материала и вывести новый грамматический алгоритм, позволяющий с уверенностью говорить о том, каким образом различать, занимает ли группа существительного с предлогом für новое место (позицию) или прежнее место (позицию) и как от занимаемой позиции может зависеть значение предлога. Исходя из имеющегося сейчас лингвистического материала с известной долей вероятности можно говорить о том, что предлог für, например, чаще выступает в роли правого определения и по своему значению и функции сближается с предлогом von. И в этой связи мы снова возвращаемся к проблеме правого определения, о котором шла речь в пункте 3.2 .

\section{ЛИТЕРАТУРА}

Белопольская, А. Р. (1971). “Выделение формальных лингвистических признаков как основы для построения алгоритмов.” (На материале нем.яз.) Автореферат дис. на соискание учен. степени канд. филол. наук. Ленинград.

Белопольская, А. Р. (2014). Руководство по алгоритмическому анализу немеикого текста («Путеводитель по тексту»). СПб.: Изд-во СПбГУ.

Хомский, Н. (1962). “Синтаксические структуры.” Новое в лингвистике. Выпуск II. Москва: Изд-во иностранной литературы: 412-527.

Хомский, Н., Миллер Дж. (2003). Введение в формальный анализ естественных языков. Перевод с английского Е. В. Падучевой. Москва: Едиториал УРСС.

Якобсон, Р. О. (1985). “Взгляды Боаса на грамматическое значение”. Избранные работы. Москва: Прогресс.

Мирам, Г. Э. (2005). Практический перевод. Заметки к лекциям. Киев: Ника-Центр.

Ямшанова, В. А. (2017). “Алгоритмическая грамматика: Роль артикля при анализе и переводе немецкого текста.” Metodički vidici. Novi Sad: B настоящем сборнике.

Ломтев, Т. П. (1958). Основы синтаксиса современного русского языка. Москва: Учпедгиз. 
Марина Чиканова

\section{АЛГОРИТАМСКА ГРАМАТИКА: СИНТАКСИЧКО МЕСТО И ЮЕГОВА УЛОГА У АНАЛИЗИ НЕМАЧКЕ РЕЧЕНИЦЕ}

\section{Резиме}

Један од модерних приступа у учењу страног језика у условима ограниченог временског периода је предавање страног језика на основу граматичких алгоритама. Граматички алгоритми су осмишљени узимајући у обзир формалне карактеристике различитих граматичких феномена, прописују стриктну доследност и дају могућност брзог извлачења информације из текста, тј. рад са текстом иде путем "од форме до значења". Студенти не започињу превод текста тражењем значења речи у речнику, већ дефинисањем положаја (места) које речи заузимају у реченици. Познавање формалних карактеристика помаже да се разуме смисао. Алгоритамска правила која су предложили студенти заснована су на принципу језичког изобиља и језичке економичности. Искуство предавања немачког језика на основу алгоритамског приступа доказује продуктивност и ефикасност предложеног начина обучавања. Појашњено је да се у процесу предавања користи минимални број граматичких термина (субјекат, предикат, (лева и десна) прилошка одредба. Фокус је на практичној примени правила. Овај принцип образовања такође доприноси развијању вештина превођења. Алгоритамско правило заснива се на формалним карактеристикама. Оно мора бити кратко, ако је могуће да нема изузетке, да се лако памти. Граматички алгоритми који обухватају основна граматичка правила, обрађени су раније. Међутим, појављују се такви феномени за које је неопходно креирати нове алгоритме. На пример, алгоритам, повезан са концептом синтаксичког места, који је централни у немачкој реченици, или алгоритам, који допушта да се дефинише да ли група именице са предлогом заузима "стару" позицију или "нову". Описане су формалне карактеристике "истог" места/позиције или "новог" места/позиције. У чланку се наглашава да је позиција речи у реченици очигледна и јака формална карактеристика, одређује се које језичке јединице могу заузимати независно место у реченици. На примеру групе именица са предлогом у ланцу група именица, показано је да нису до краја разрађена правила која омогућавају да се одреди да ли предлошка група заузима "стару" или "нову" позицију.

Кључне речи: настава страног језика, немачки, систем наставе, алгоритамска граматика, алгоритам, формалне карактеристике, синтактичко место, група именица, ланац група именице, предлог.

Primljeno: 1.5.2017. Prihvaćeno: 5.9.2017. 